\title{
Institucionalidad regional en la Argentina reciente: el dilema de la política pública de desarrollo regional
}

Martín Seval

Doutorando em Geografia na Universidad de Buenos Aires, Argentina (UBA)

José Ignacio Vigil

Faculdade de Ciências Econômicas da Universidad Nacional del Litoral, Argentina (UNL)

Victor Ramiro Fernández,

Faculdade de Ciências Econômicas da Universidad Nacional del Litoral, Argentina (UNL)

Recebido: 29/11/2013 Versão revisada (entregue): 06/12/2013 Aprovado: 09/12/2013

\section{Resumen}

La estrategia de desarrollo regional argentina promueve la institucionalidad regional como intermediaria entre la política pública y sus destinatarios. Se considera a la intermediación institucional como garantía de mayor efectividad y apertura democrática. Sin embargo, en la práctica observamos la continuidad de asimetrías y retraso democrático. Entendemos este problema práctico desde un problema teórico en la política pública. La estrategia de desarrollo regional adopta aportes nuevo-regionalistas cercanos a la cohesión regional sin considerar posturas críticas. Nuestra propuesta se centra en una revisión teórico/empírica de la relación institucionalidad-heterogeneidad regional, tomando un estudio de caso para enfrentar el dilema de discutir una estrategia ampliamente difundida en el desarrollo regional.

Palabras-clave | Argentina; desarrollo regional; heterogeneidad regional; intermediación institucional; políticas públicas.

Código JEL | O21; R11; R58.

\section{INSTITUCIONALIDADE REGIONAL NA ARGENTINA RECENTE: O DILEMA DA POLÍTICA PÚBLICA DE DESENVOLVIMENTO REGIONAL}

\section{Resumo}

A estratégia de desenvolvimento regional argentina trata a institucionalidade regional como intermediária entre a política pública e seus destinatários. Pressupõe-se que a intermediação institucional seja garantia de maior efetividade e abertura democrática. Na prática, contudo, observa-se a permanência de assimetrias e déficit democrático. Entende-se este problema concreto desde uma perspectiva teórica na política pública. A estratégia de desenvolvimento regional funda-se em aportes neo-regionalistas, próximos à coesão regional, que, porém, 
desconsideram posturas críticas. A proposta neste artigo centra-se em uma revisão teóricoempírica da relação institucionalidade-heterogeneidade regional, tomando um estudo de caso para enfrentar o dilema de discutir uma estratégia que tem sido amplamente difundida no desenvolvimento regional.

Palavras-chave | Argentina; desenvolvimento regional; heterogeneidade regional; intermediação institucional; políticas públicas.

Código JEL | O21; R11; R58.

\title{
REGIONAL INSTITUTIONS IN RECENT ARGENTINA: THE DILEMMA OF PUBLIC POLICY ON REGIONAL DEVELOPMENT
}

\begin{abstract}
The regional development strategy in Argentina promotes regional institutions as intermediaries between the public policy and its recipients. The institutional intermediation is seen as a guarantee for greater effectiveness and democratic openness. Nevertheless, in practice we observe the continuity of asymmetries and democratic delay. We understand this practical problem as drawing from a theoretical problem in public policy. The regional development strategy adopts regional cohesion-based new-regionalist contributions, leaving aside critical positions. We propose a theoretical/empirical review of the relationship between institutions and regional heterogeneity, taking a case study to face the dilemma of discussing a widely disseminated strategy in regional development.
\end{abstract}

Keywords | Argentina; institutional intermediation; public policies; regional development; regional heterogeneity.

JEL-Code | O21; R11; R58.

\section{Introducción}

En la última década han sido impulsadas en Argentina una serie de políticas públicas orientadas a fomentar aglomeraciones productivas de pequeñas y medianas empresas (pyme) a través de la organización y consolidación de la institucionalidad regional. Instaladas como herramientas de desarrollo regional, este tipo de política se vincula a la difusión de estrategias de desarrollo replicadas en países centrales y periféricos en el marco del auge nuevo-regionalista. El caso argentino coincide con la discusión y la construcción discursiva de un modelo de desarrollo que le otorga relevancia a la industria nacional (MI, 2011; MPFIPS, 2004) y específicamente a las regiones productivas pyme (DONATO, 2010; SEPYME, 2005).

Los conceptos que se aplican al impulso de la dinámica regional y que derivan de la (re)discusión de los enfoques regionalistas suelen trabajar desde el lado de la oferta regional. En este sentido, conceptos como gobernanza o densidad institucional (entre otros) estimulan la asociación y la cooperación entre actores 
regionales. En un contexto de aplicación de política pública estos conceptos sugieren que la institucionalidad regional esté presente entre la política y los destinatarios de la misma. A este proceso lo llamaremos intermediación institucional regional.

La intermediación institucional se incorpora al debate a partir de dos argumentos centrales. Por un lado, se la vincula a la efectividad de la política. De la calidad de la institucionalidad regional depende la promoción de actividades innovadoras, la difusión y transferencia de conocimiento y la provisión de servicios empresariales (BRACZYK; COOKE; HEIDENREICH, 1998; COOKE; MORGAN, 1990; 1998). Por otro lado, se la vincula a la inclusión. Se destaca su capacidad de reducir el déficit democrático (AMIN, 1999; AMIN; THRIFT, 1994; 1995) en la definición de los objetivos regionales.

Sin embargo, cuando la política pública adopta estas bases conceptuales la intermediación institucional es impulsada a partir de un imaginario geográfico de homogeneidad regional que sostiene un imaginario democrático de horizontalidad entre los actores regionales. Aun cuando ha habido importantes avances para detectar las heterogéneas composiciones internas de los sistemas productivos regionales, la política pública adopta una marcada tendencia en las bases conceptuales nuevo-regionalistas a evitar el conflicto en favor de la cohesión regional y sobrevalorar la armonía y la construcción colectiva de objetivos comunes a partir de la colaboración y la cooperación entre los actores regionales.

Nuestro trabajo sostiene que se instala una paradoja en la aplicación concreta de este tipo de política pública. En la práctica suele ocurrir que las acciones concretas impulsadas encuentran un fuerte vínculo con los objetivos particulares de ciertos grupos de actores regionales aunque sean presentados como objetivos regionales. Estos grupos suelen monopolizar los canales institucionales y tienen la capacidad de redirigir los objetivos de los programas en beneficio propio, por lo que se tergiversa el sentido de la política que se propone más efectiva, inclusiva y democrática.

Identificada esta paradoja, buscamos enfrentar a la política pública al dilema de discutir un esquema que a primera vista es contradictorio en sus logros respecto de lo inclusivo de su propuesta de desarrollo regional. El desafío refiere al abordaje de la política pública desde la revisión de su sustento teórico y de su forma de aplicación. Para ello el artículo se estructura en cuatro apartados. El primer apartado (contextual) presenta la política pública regional argentina, identificando las principales características que adopta la intermediación institucional regional. El segundo apartado (teórico) indaga los enfoques que justifican la intermediación institucional al momento de aplicar la política regional y destaca la necesidad de superar la mirada homogeneizadora incorporando criterios de heterogeneidad para analizar sistemas productivos e institucionales. El tercer apartado presenta un caso concreto, la Región de la Maquinaria Agrícola 
argentina, que se analizará en el cuarto apartado para dar cuenta de la estrecha articulación entre la beterogeneidad del sistema productivo y el sistema institucional. A modo de conclusión, unas breves reflexiones cierran el artículo.

\section{Políticas nuevo-regionalistas e institucionalidad regional: el problema práctico}

La crisis que atravesó Argentina entre 2001 y 2002 suele verse como un punto de inflexión respecto a la reestructuración industrial que se extendió entre las décadas del '70 y el '90 del siglo XX. Los cambios macroeconómicos de la posconvertivilidad ${ }^{1}$ significaron un fuerte impulso a la producción nacional y a su capacidad instalada. A partir de entonces, a la par del comportamiento positivo de la actividad industrial en general, la política pública buscó fomentar a las pymes. Un ejemplo es el de las políticas de desarrollo regional y el fomento de aglomeraciones productivas pyme como una herramienta de desarrollo.

Esta etapa ha venido de la mano de la promoción de los conceptos de industria, pyme y región, una triada conceptual resaltada desde su interacción virtuosa. En los programas estratégicos oficiales se ha consolidado en la última década la presentación de la industria nacional como motor de crecimiento, generador de trabajo y valor agregado, asignándole a las pyme un rol clave para favorecer equilibrios regionales e inclusión social (MPFIPS, 2004; MI, 2011; 2013). En este contexto las regiones fueron señaladas como sitios estratégicos desde donde pensar la acumulación económica, al reconocerles características socioculturales que le dan una impronta particular para el desarrollo de sistemas productivos pyme con cierta especialización productiva.

En ese marco, la triada conceptual incorpora una dimensión institucional. Se delega en la intermediación institucional regional la aplicación de los instrumentos de política pública. Es decir, la institucionalidad regional es la encargada de aplicar los programas concretos, definiendo objetivos, plazos, estrategias y el ámbito espacial de aplicación de la política pública, y con ello un perfil de destinatario. Se espera una mayor receptividad porque se supone la inclusión de nuevas voces y demandas al diseño y aplicación de las políticas regionales, identificando desde la región los objetivos de la interacción con el Estado nacional, lo que recuerda el paso de la idea de gobierno a la de gobernanza (VIGIL; FERNÁNDEZ, 2011). El

\footnotetext{
${ }^{1}$ La convertibilidad fue el tipo de cambio que operó en el sistema monetario argentino entre 1991 y 2002 (Ley 23.928, Decreto 2128/91, Decreto 471/02). Establecía la relación cambiaria fija entre la moneda argentina y el dólar estadounidense. Inicialmente se aplicó a la moneda de curso legal en 1991 (el austral), remplazada en 1992 por el peso, en su relación 1 a 1 respecto al dólar. La convertibilidad dio continuidad e intensificó un período neoliberal privatizador y desindustrializador iniciado en la década del ` 70.
} 
empoderamiento de los actores regionales se promueve con el traspaso de la capacidad de decisión y de gestión del desarrollo, en el que la calidad de la institucionalidad regional carga con la responsabilidad del éxito de la política.

Dos programas concretos que vinculan innovación e industria son ilustrativos: El Proyecto Integrado de Aglomerados Productivos (PI-TEC) y el programa de Sistemas Productivos Locales (SPL) ${ }^{2}$. El desembarco de este tipo de programa en regiones concretas es un ejemplo de los acuerdos que el Estado argentino mantiene con organismos supranacionales como el Banco Interamericano de Desarrollo y el Programa de las Naciones Unidas para el Desarrollo, que habilitan financiamiento vinculado a sistemas productivos regionales.

Figura 1 - Argentina: esquema de aplicación del Programa PI-TEC y el Programa SPL

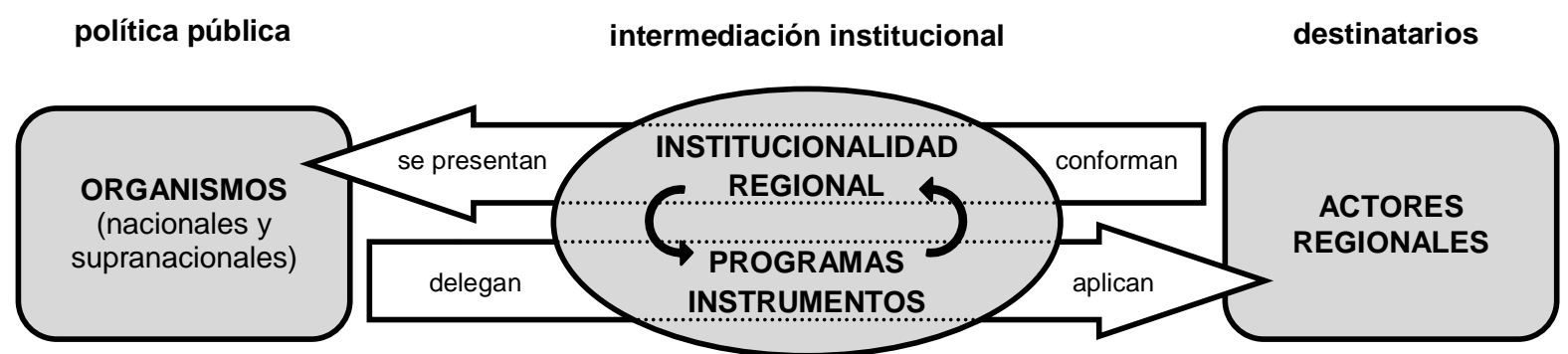

Fuente: Elaboración propia en base a ANPCYT (2010a), SEPYME (2011) y Naclerio (2010).

En ambos casos se exige un soporte institucional ubicado entre los organismos que diseñan la política y los actores regionales que serían sus destinatarios finales. El PI-TEC promueve un proceso asociativo empresario-institucional para conformar una Asociación ad-hoc que designa a la unidad ejecutora del programa regional. El SPL se aplica a grupos empresariales con antecedentes de acción asociativa, al tiempo que promueve mayores vinculaciones con las instituciones regionales para llevar adelante un plan de trabajo asociativo. Habilitando en el primer caso la coordinación de instrumentos de financiamiento ${ }^{3}$ destinados a investigación, desarrollo y modernización tecnológica de los sistemas productivos regionales, y en el segundo caso promoviendo aglomeraciones productivas tipo cluster y/o redes de grupos empresariales. Ambos casos siguen el esquema de la figura I, en el que los actores regionales se organizan y conforman acuerdos institucionales para presentarse ante los organismos que diseñan la política, los

\footnotetext{
${ }^{2}$ El PI-TEC es un programa de ANPCYT: Agencia Nacional de Promoción Científica y Tecnológica (Ministerio de Ciencia y Tecnología). El SPL es un programa de SEPYME: Secretaría de la Pyme y Desarrollo Regional (Ministerio de Industria).

3 Dos fondos de financiamiento merecen ser mencionados. FONCYT: Fondo para la Investigación Científica y Tecnológica. Financia la generación de conocimientos científicos y tecnológicos. FONTAR: Fondo Tecnológico Argentino. Financia proyectos de innovación, de investigación y desarrollo, modernización tecnológica, patentamiento, etc.
} 
cuales delegan la aplicación de los programas y los instrumentos de política pública a la institucionalidad regional resultante.

Ahora bien, en esa intermediación institucional regional se habilita la apertura a redes de relaciones entre actores económicos, productivos e institucionales, públicos y privados, con diferente grado de influencia para articular intereses y fijar agendas. Es en ese marco que nos surgen interrogantes sobre el rol dado a la construcción de la institucionalidad regional. Podría ocurrir que los actores económicos con mayor capacidad decisoria sean también aquellos que finalmente protagonizan la interacción con la política pública y dirijan la definición de los intereses regionales. La paradoja estaría dada entonces por considerar que la institucionalidad regional es la mejor manera para fomentar el desarrollo regional al tiempo que es donde se construyen alianzas selectivas, se fomentan objetivos particulares, se concentra el poder decisional y se capitaliza una política supuestamente inclusiva. En este sentido, a continuación, proponemos realizar una exploración de los fundamentos y las debilidades de las bases teóricos de la política pública.

\section{Nuevo regionalismo, instituciones y sistemas productivos: el problema teórico}

La forma en que la política pública asigna un lugar central a la intermediación institucional regional posee bases teóricas que justifican su rol en la aplicación de los programas de desarrollo. De este marco conceptual nos interesa aquí revisar de forma crítica dos debates: por un lado, el debate sobre las ventajas de las instituciones locales en los procesos de desarrollo y, por otro lado, el debate crítico sobre las características de los sistemas productivos regionales. Con ello buscamos advertir que si bien ambos debates tienen importantes potencialidades, su desconexión teórica al momento de ser adoptados por la política pública repercute en limitaciones del marco teórico que dan lugar a la paradoja en la aplicación práctica de la política en cuestión.

\section{La institucionalidad regional en los procesos de desarrollo}

A fines de la década del 70 , en un contexto de crisis del modelo fordistakeynesiano, el debate en torno a los sistemas productivos regionales experimenta una renovación teórica. Comienza un derrotero de nuevos estudios regionalistas, posteriormente reconocidos bajo el nombre de Nuevo Regionalismo (KEATING, 1998), que encuentran la explicación del buen desempeño de ciertas regiones subnacionales ante la crisis en la dimensión institucional de sus sistemas productivos. Las regiones ganan peso en el debate académico a la par de la incorporación de la 
dimensión institucional como un elemento cualitativo de exploración, habilitando el abordaje de lo económico como un proceso socio-cultural que también involucraba factores no económicos (HADJIMICHALIS, 2008).

A partir de ese momento los aportes institucionalistas se vinculan con enfoques que explican la emergencia de las regiones destacando la cohesión regional, se alejan del análisis de conflictividad propia de abordajes marxistas y se acercan a criterios de homogeneidad y armonía entre los actores regionales. Desde los pioneros distritos industriales se abordó a los sistemas productivos regionales como conglomerados sin centro de decisiones con actores de un tamaño específico que actúan con coherencia y unidad regional (ver BAGNASCO, 1977; BRUSCO, 1982; 1992; BECATTINI, 1987) en la creación y difusión de conocimiento por medio de procesos colectivos e impregnantes (GIULIANI, 2005) y en la generación de competitividad a través de la canalización de los intereses comunes $y$ complementarios de los actores regionales. En este contexto interpretativo, la vecindad que deriva de la aglomeración traería beneficios a nivel regional que darían respuesta a los intereses de todos los actores de la región (LOVERING, 1999), desde el acceso como bien público a los saberes de la industria (BECATTINI, 1990), el derrame del conocimiento y la innovación como proceso evolutivo y social (DOLOREAUX; PARTO, 2005), hasta la competitividad empresarial individual que se constituye en competitividad regional (PORTER, 1990; 1998).

En este debate se enfatiza desde la dimensión institucional el rol del elemento cooperativo y organizacional del nivel regional al momento de señalar las ventajas de las instituciones en los procesos de desarrollo. Lo cooperativo fue resaltado como un emergente de valores culturales arraigados en el tiempo y compartidos en el presente que mejoran el contexto donde se producen las relaciones de producción regionales por los lazos de confianza y reciprocidad que generan (AMIN, 1999; BECATTINI, 1990; PUTNAM; LEONARDI; NANETTI, 1993; RODRIGUEZPOSSE, 1999; STORPER, 1997). Lo organizacional surge de objetivos comunes compartidos también desde lo cultural pero con repercusión en estructuras formales que permiten la asociatividad y la generación de actores colectivos. En este sentido, la densidad institucional (AMIN; THRIFT, 1994; 1995) es entendida desde lo cualitativo de la interacción entre las diversas organizaciones que representan a los sectores económicos y sociales de una región.

La dimensión institucional y los sistemas productivos quedan vinculados en una forma de abordar el estudio de las regiones que supone cierta homogeneidad de actores regionales $\mathrm{o}$, al menos inicialmente, no interpreta que sus diferencias alteraran el esquema conceptual. En este sentido, entendemos lo atractivo del marco teórico nuevo-regionalista para los policy-makers a partir de dos imaginarios regionales. Por un lado, un imaginario geográfico. Se genera una imagen de homogeneidad regional al limitar la heterogeneidad a la diferencia entre regiones, habilitando estudios comparados para la identificación de estructuras modelo a 
reproducir. Por otro lado, un imaginario democrático. Al resaltar los elementos de unión regional, se genera una imagen de horizontalidad que permite delegar la aplicación de la política pública a los actores locales, sólo concebible en un contexto regional sin conflictos, coherente y armónico.

En síntesis, la intermediación institucional toma relevancia para la política pública en un contexto que desatiende el análisis de respuestas no tan armónicas a los conflictos $^{4}$. Lo problemático radica en que se favorece la homogeneización de los procesos y sus resultados, minimizando las divisiones sociales en las regiones (WALKER, 1998) y desconsiderando criterios vinculados al poder y al conflicto (CUMBERS; MACKINNON; MCMASTER, 2003). Aquí yace la importancia de estudiar los grupos de actores regionales e identificar aquellos grupos que concentran la toma de decisiones y del modo en que lo hacen respecto de su posicionamiento (probablemente) como grandes actores económicos.

\section{Las heterogeneidades desde el estudio de los sistemas productivos regionales}

A fines de la década del ' 90 , una serie de aportes teóricos incorporaron las diferencias entre los actores regionales de forma explícita al debate sobre sistemas productivos regionales al advertir que gran parte del debate daba lugar a la idea de homogeneidad ${ }^{5}$. Se problematizó la existencia de heterogeneidades luego de haber hecho hincapié en la construcción de tipologías de sistemas productivos del tipo sticky places (MARKUSEN, 1996) o núcleo-balo (STORPER; HARRISON, 1994). Tipologías que cuestionaron la idea de un modelo único de sistema productivo que incluso involucró la discusión de la existencia del distrito industrial canónico italiano (PANICCIA, 1998; 1999). Sin embargo, aquí nos interesa destacar un paso posterior, aquel que realizaron una serie de aportes sobre heterogeneidades internas que, en palabras de Rabellotti; Schmitz (1999), instauran una etapa más madura en torno al estudio de las heterogeneidades. A través de la identificación de grupos de actores regionales diferenciados en base a la dimensión económica, estos aportes indagan los procesos que supuestamente potencia la proximidad

\footnotetext{
${ }^{4}$ Es el caso de los corporativismos regionales con esclerosis institucional (AMIN, 1999), coaliciones que bloquean procesos de innovación y de distribución de recursos, coaliciones regresivas (BIANCHI; MILLER, 2000) que sostienen un status quo.

${ }^{5}$ Según Molina-Morales; Martínez-Fernández (2009) la homogeneidad fue asumida por los estudios regionales sin haber sido confirmada. Rabellotti; Schmitz (1999) afirman que sólo se introduce la diferenciación en referencia a procesos y productos, obviando variables como tamaño, performance, innovación tecnológica, segmento de mercado, marketing, vínculos empresa-asociaciones. Similar aporte realizan Shaver; Flyer (2000) identificando: tecnología, capital humano, entrenamiento y proveedores/distribuidores, aunque tomando al tamaño como promedio del sistema.
} 
física. La discusión enfatiza lo selectivo y conflictivo de estos procesos, sentando las bases para una ruptura con el imaginario geográfico de homogeneidad regional y el imaginario democrático de horizontalidad.

El tamaño de las unidades productivas y el performance de las empresas son señalados en varios estudios teórico-empíricos como los principales factores en la determinación de las heterogeneidades (ver RABELLOTI, 1999; RABELLOTTT; SCHMITZ, 1999). A través de tipologías internas que agrupan actores regionales por afinidad con ambas variables es posible analizar el comportamiento de tres tipos de procesos. En primer lugar, las prácticas cooperativas y el aprovechamiento de las externalidades derivadas de la aglomeración, en segundo lugar, las formas de creación y circulación del conocimiento y la de introducción de innovaciones y, finalmente, las características de las redes que construyen y con las que se conectan. Inicialmente identificados como procesos armónicos, la heterogeneidad interna permite distinguir sus aspectos selectivos y conflictivos.

La relación positiva entre cooperación y performance toma características particulares desde planteos que entienden los procesos cooperativos como procesos selectivos (SCHMITZ, 1999; 2000). La proximidad física no garantiza comportamientos generalizados por lo que el enraizamiento local varía en relación al performance y el tamaño de las empresas (RABELLOTTI; SCHMITZ, 1999). Las empresas más grandes y con un mejor performance tienden a alejarse de las empresas más pequeñas, incluso a nivel de localización física, por los efectos negativos derivados de las contribuciones asimétricas de la interacción directa o indirecta con empresas que no realizan aportes significativos (SHAVER; FLYER, 2000). En este contexto, las empresas más pequeñas desarrollan comportamientos individualistas debido al menor involucramiento en acciones colectivas (RABELLOTTTI; SCHMITZ, 1999).

Lo colectivo e impregnante de la creación y la difusión de conocimiento se ve limitado en un contexto de heterogeneidad interna (GIULIANI, 2005) a partir del carácter selectivo que adopta la circulación de la información, en cuanto a la predisposición para ofrecerla y la capacidad de codificarla. La reciprocidad al momento de compartir información influye en el comportamiento de los actores regionales. Generalmente los grandes actores optan por desarrollar conexiones externas y los pequeños actores menos innovadores quedan atados a vínculos locales sin garantía de resultados positivos (Molina-Morales; Martínez-Fernández, 2009). La construcción diferencial de conocimiento de base (GIULIANI; BELL, 2005) y los diferentes niveles de aprendizaje (MASKELL, 2001; MARTIN; SUNLEY, 2003) fomentan de esta manera el carácter selectivo que adopta la información y el conocimiento, haciendo que quienes logren una asimilación temprana se posicionen en mejores condiciones para la asimilación a futuro de información y conocimiento más cualificado. 
Las similitudes de comportamiento ante lo selectivo de la cooperación y de la circulación de conocimiento encuentran explicación en la heterogénea capacidad de los actores regionales para vincularse mutuamente y los heterogéneos resultados en la construcción de redes. La heterogeneidad es esperable en todo tipo de red social (MCEVILY; ZAHEER, 1999), por lo que al analizar las redes regionales a través de la construcción de tipologías, según Morrison; Rabellotti (2005, 2009), se detectan como mínimo dos categorías. Por un lado, las redes de actores que dependen de las dinámicas regionales (corenetwork), generalmente pequeñas empresas que optan por fuertes lazos regionales al accionar individual. Por otro lado, las redes de aquellos actores que se vinculan a la dinámica regional a través de redes dispersas (peripherynetwork), generalmente grandes empresas que tienen la capacidad operativa interna para vincularse con actores externos. Los resultados de ambos tipos de redes son diferentes porque las empresas del núcleo central se enfrentan a los efectos negativos de la pertenencia al club (MOLINAMORALES; MARTÍNEZ-FERNÁNDEZ, 2009). Mantener fuertes vínculos requiere dedicación, las empresas terminan vinculándose con pocos actores regionales, pierden flexibilidad y autonomía, ya que el vínculo infiere un control compartido. Es decir, aunque en el núcleo central se observe mayor grado de cooperación, es al interior de las redes periféricas donde se despliegan los mayores niveles de innovación.

En síntesis, queremos destacar dos importantes características de esta discusión:

i) El reconocimiento de la existencia de la diversidad de configuraciones de los sistemas productivos regionales. De utilidad no sólo para la diferenciación entre sí, sino para reconocer diferencias en ellos e identificar la constitución de grandes actores.

ii) La incorporación parcial de la dimensión institucional al estudio de la heterogeneidad en los sistemas productivos. Se adentran en la dimensión institucional sólo para analizar la influencia de la dimensión económica en las prácticas de los actores regionales.

Las características señaladas resumen la contribución al debate de la intermediación institucional por parte de los aportes de heterogeneidades. Si bien no dan cuenta cómo la heterogénea capacidad de vinculación de los actores regionales influencia a la estructura organizacional, sientan las bases para una ruptura con el imaginario geográfico de homogeneidad regional y el imaginario democrático de horizontalidad. Es decir, aunque no permitan abordar de forma directa el proceso por el cual los grandes actores económicos encuentran una particular conexión con los actores institucionales, proporcionan herramientas conceptuales para avanzar en esa dirección al afirmar no sólo la existencia de heterogeneidad sino también su influencia en las prácticas de los actores regionales. 


\section{Las desconexiones teóricas en la política pública: limitaciones y potencialidades}

La política pública habilita la intermediación institucional regional a partir del reconocimiento teórico nuevo-regionalista de la capacidad cooperativa y organizacional en la resolución de los problemas de desarrollo con impronta regional. Sin embargo, el empoderamiento de los actores regionales se da: (1) aplicando un esquema no conflictivo que prioriza la cohesión regional (2) sin atender a las heterogeneidades internas de sus sistemas productivos.

La desvinculación entre ambas discusiones en la aplicación de la política pública convierte en un problema teórico al problema práctico detectado en la paradoja de las políticas de desarrollo regional. Los planteos de los aportes regionalistas que dejan la incógnita del rol de los actores institucionales en la aplicación de la política pública quedan desvinculados de los abordajes que abordaron explícitamente las heterogeneidades en los sistemas productivos regionales, los cuales permitirían detectar la constitución de esos grandes actores económicos. En el próximo apartado se busca evidenciar las consecuencias que esto trae aparejado a través del análisis del desembarco de la política pública en un caso específico, el caso de la Región de la Maquinaria Agrícola argentina.

\section{La Región de la Maquinaria Agrícola: el problema de la política pública argentina desde un caso de 'intermediación institucional regional'}

La presentación de la Región de la Maquinaria Agrícola (RMA) busca mostrar inicialmente la manera en que la política pública descansa sobre una intermediación institucional regional. En el caso de estudio, el ingreso de la política pública se explica por el interés político-institucional que ha cobrado la región debido a la importancia que presenta la maquinaria agrícola para el modelo de crecimiento hacia afuera promovido por el estado nacional desde el año 2002 (GARCÍA, 2008) y por esquemas provinciales de fomento de la industria (GSF, 2009), posicionándose como sujeto de desarrollo en el escenario económico argentino (NACLEIRO, 2010; NARODOWSKI, 2007). El resultado de esta atención político-institucional incluye ser beneficiada por la política de aglomeraciones pyme, en el marco de la cual se adopta el formato cluster y se constituye el Cluster de la Maquinaria Agrícola (CMA).

Precisamente el proceso de intermediación institucional propuesto en la región se da en torno a la conformación del CMA, una asociación de empresas y organizaciones civiles y estatales a la que se le atribuye el rol de definir las estrategias de aplicación de la política pública. Entre ellas, definir el ámbito territorial, es decir, los actores que aplican la política pública (estableciendo 
objetivos y acciones concretas para llevarlos a cabo) también tienen la capacidad de delimitar y determinar indirectamente quienes son los posibles beneficiarios de los programas de promoción. La RMA queda circunscripta para la política pública a los dos anillos que definen al CMA (ver Figura 2). Según el programa de fomento pyme, la región está constituida principalmente por una red de cuatro ciudades de la Provincia de Santa Fe y Córdoba ${ }^{6}$ con una importante representación (nacional y provincial) en el sector de la metalmecánica y específicamente de la maquinaria agrícola ${ }^{7}$.

Figura 2 - CMA: ámbito territorial de influencia. Nodo central y anillo periférico del Cluster definido por la aplicación de programas de fomento de aglomeraciones productivas pyme

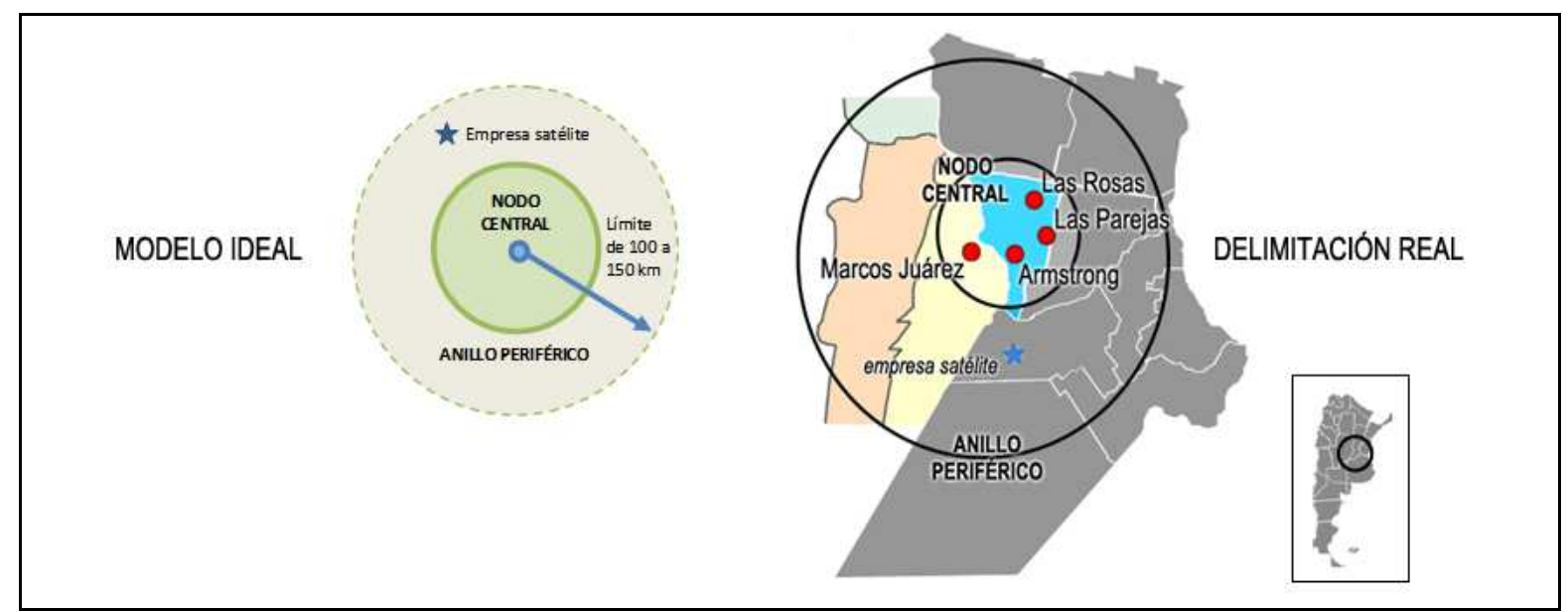

Fuente: CECMA-CIDETER; Mascheroni (2009), CECMA (2011; 2012).

Como hemos indicado, la aplicación de dicha política pública se realiza a través de una intermediación institucional constituida por una asociación de empresas y organizaciones ad-hoc que ejecuta la política ${ }^{8}$. La figura 3 muestra la forma en que la construcción de la intermediación institucional se define teniendo en cuenta el esquema de aplicación de la política pública de fomento a aglomeraciones productivas (comparar con Figura 1). Se potencia la institucionalidad regional a través de la articulación de una red de organizaciones y empresas asociadas para cooperar, considerando la existencia de una base de relaciones armónicas motivadas por una misma finalidad. La intermediación institucional regional es

\footnotetext{
${ }^{6}$ Armstrong, Las Parejas y Las Rosas (suroeste de Santa Fe) y Marcos Juárez (este de Córdoba).

${ }^{7}$ Santa Fe concentra casi el 50\% de los establecimientos de la maquinaria agrícola de la Argentina y las cuatro localidades de la RMA contienen cerca de 200 firmas especializadas. (CECMA-CIDETER; Mascheroni, 2009)

${ }^{8}$ Clave en ese proceso ha sido Fundación CIDETER, organización de ciencia y técnica local que actuó como nexo entre los organismos estatales y los actores regionales para el ingreso de la política pública y los programas de SEPYME y ANCYPT.
} 
depositaria de la política nacional (programas y líneas de financiamiento) y articuladora de los destinatarios finales (empresas). En este rol se le demanda que (1) establezca los objetivos del programa, (2) genere las herramientas para alcanzarlos y, como fuera señalado, que defina (3) los límites espacial de la RMA y, por lo tanto, (4) los posibles beneficiarios del accionar de la política pública y sus líneas de financiamiento.

Figura 3 - CMA: construcción de la intermediación institucional del Cluster de la Maquinaria Agrícola

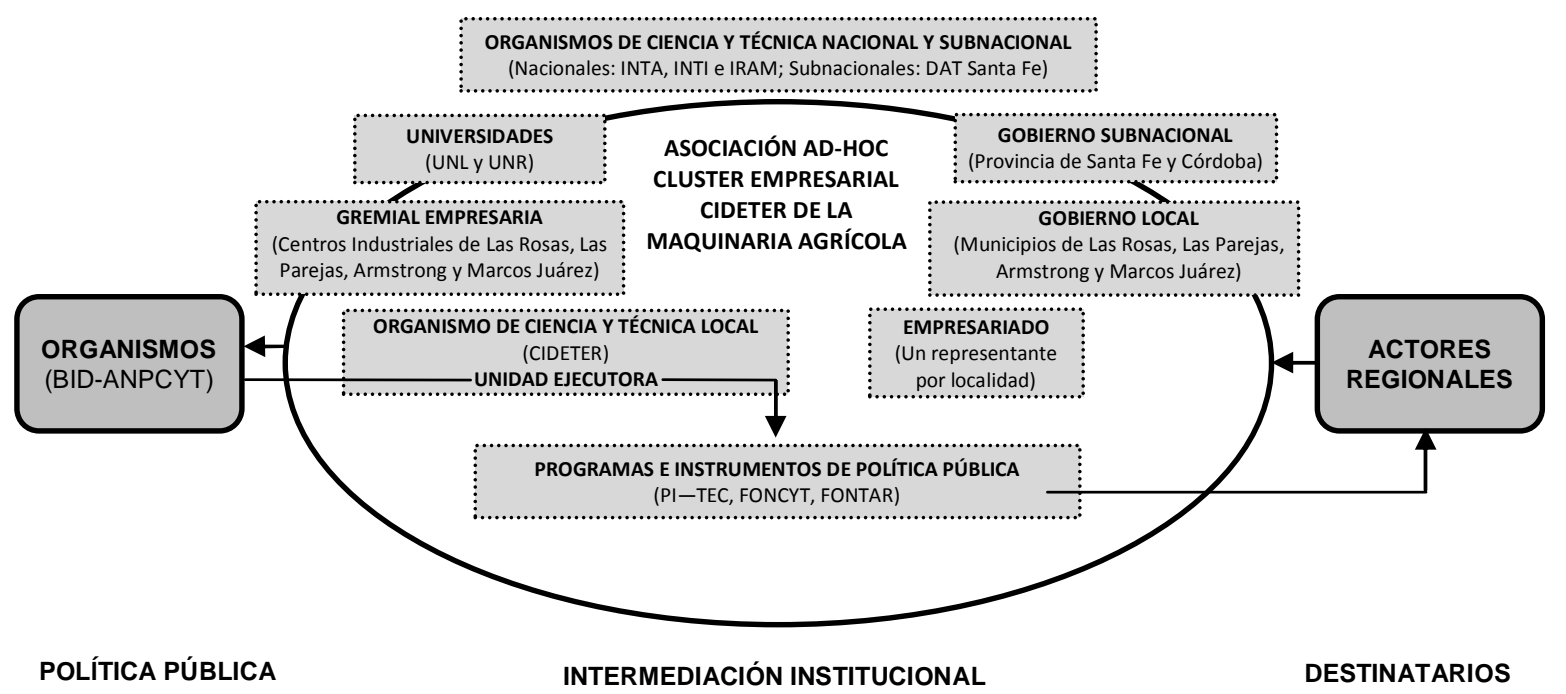

Fuente: Elaboración propia en base al acta constitutiva del CECMA (2006a) y entrevistas (2009).

Los objetivos de la política se hacen explícitos en el plan de mejoramiento de la competitividad que planteó la institucionalidad regional, documento que da cuenta de acciones concretas y proyectos específicos a seguir (CECMA, 2006b). En este sentido, el objetivo central que tiene la aplicación de la política pública podría definirse en relación al acercamiento entre las instituciones de ciencia y tecnología y las empresas pertenecientes al aglomerado productivo con el fin de fortalecer la inserción internacional de las empresas de la RMA. Para cumplir con este objetivo se prevé la apertura de líneas de financiamiento y la inversión en infraestructura de uso común generando condiciones para el mayor acceso al desarrollo tecnológico.

Otra estrategia adoptada es el impulso a la acción conjunta cooperativa para concretar los objetivos señalados. Como lo muestra lo cuadro 1, se potencian ambientes institucionales que responden a una serie de objetivos específicos (columna izquierda). La forma de resolverlos y/o concretarlos (columna derecha), si bien involucra acciones de cooperación que venían desarrollándose con anterioridad, se centra en la generación de acciones de cooperación que tienen inicio tras la aplicación de la política pública, con la particularidad de que este nuevo panorama cooperativo apunta a la internacionalización del RMA. 
Cuadro 1 - CMA: panorama cooperativo fomentado por el Cluster de la Maquinaria Agrícola

\begin{tabular}{|l|l|}
\hline Objetivo & Acción de cooperación \\
\hline $\begin{array}{l}\text { Aumentar } \\
\text { exportaciones }\end{array}$ & Pool de venta a través de la promoción de exportación. \\
\hline Reducir costos & Pool de compra conjunta de insumos. \\
\hline Obtener escala & Producción conjunta para el mercado nacional y el mercado internacional. \\
\hline $\begin{array}{l}\text { Buscar } \\
\text { competitividad }\end{array}$ & $\begin{array}{l}\text { Incorporación de tecnología e innovación con herramientas FONCYT y FONTAR } \\
\text { yor convenios asociativos con INTA (certificaciones) y con diversos } \\
\text { organismos de ciencia y técnica nacional e internacional (articulación } \\
\text { multinivel). }\end{array}$ \\
\hline $\begin{array}{l}\text { Calificar mano de } \\
\text { obra }\end{array}$ & $\begin{array}{l}\text { Capacitación tanto del nivel obrero como del nivel gerencial por medio de } \\
\text { acuerdos marco con universidades. }\end{array}$ \\
\hline $\begin{array}{l}\text { Abrir mercados } \\
\text { externos }\end{array}$ & $\begin{array}{l}\text { Vinculos internacionales como ronda de negocios, misiones inversas, ferias } \\
\text { internacionales, grupos asociativos exportadores, créditos para exportar, etc. }\end{array}$ \\
\hline
\end{tabular}

Fuente: Elaboración propia en base a información documental.

Hasta aquí la aplicación de la política pública no incorpora elementos que tengan que ver directamente con las características del sistema productivo. La principal preocupación gira en torno a trabajar sobre la continuidad institucional existente y proponer acciones que se promuevan desde su rol de intermediación institucional. Queda ausente la incorporación al debate de las diferencias existentes entre los actores empresariales de la región y cómo ellas pueden repercutir en los objetivos propuestos. Por el contrario, se enumeran fortalezas, oportunidades, debilidades y amenazas comunes a todos los actores empresariales que conforman el sistema productivo del CMA (CECMA, 2012) y se presentan resultados positivos en cuanto a la región como un todo (ver Figura 4 y 5). En este sentido, al momento de la evaluación de sus resultados este esquema tiende a considerar los logros comunes conseguidos y los desafíos comunes superados, con documentos estilo inventario que muestran proyectos finalizados para verificar que el esquema está en funcionamiento.

Esta idea de lo común genera una serie de interrogantes ¿Hasta qué punto estas cualidades y problemáticas comunes no forman parte de un discurso de cierto grupo de actores regionales que pueden hablar en nombre de generalizando sus intereses particulares? $Y$ en este sentido pero analizando resultados ¿Es válido considerar los logros comunes como logros de una región? Entendiendo la posible conexión entre elites económicas y elites institucionales, además cabe preguntarse ¿Qué conexión tiene este proceso, propio de la dimensión institucional, con la heterogeneidad del sistema productivo y cómo esto puede explicar los resultados de la política pública? 
Figura 4 - CMA: ventas (2002-2010)

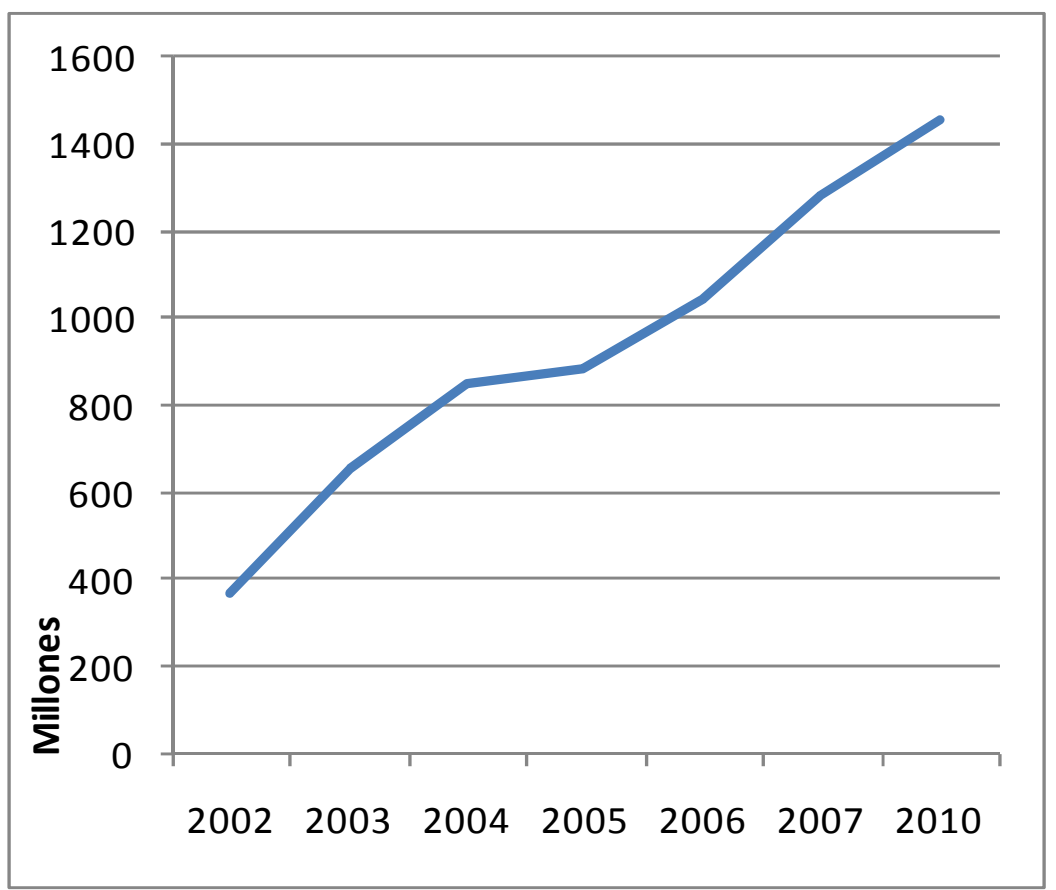

Fuente: CECMA (2012).

Figura 5 - CMA: exportación según ventas (2002-2010)

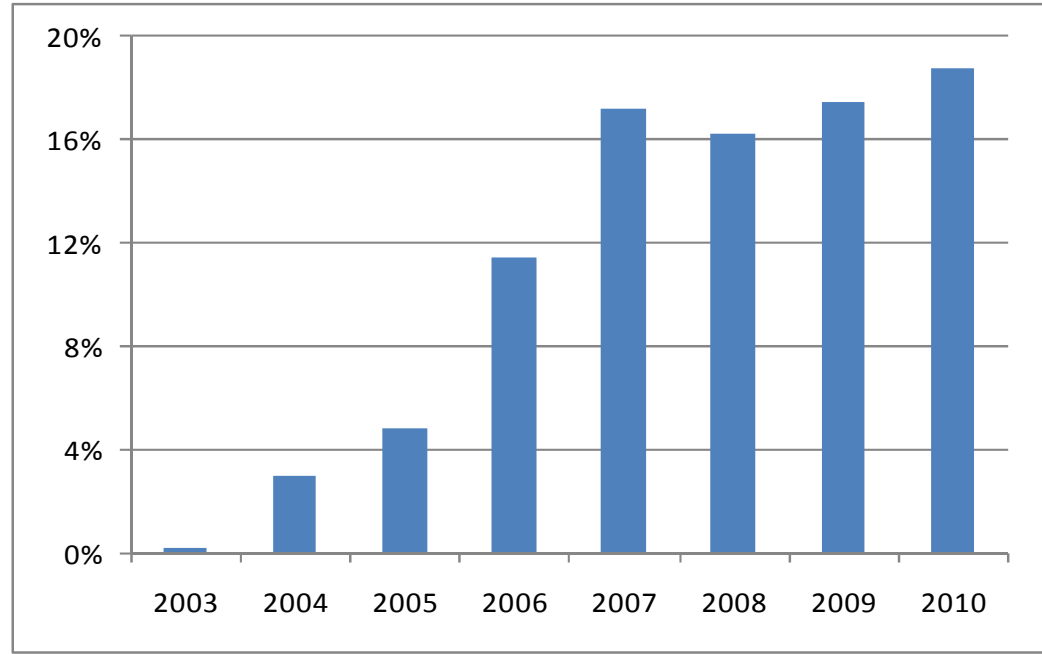

Fuente: CECMA (2011).

La heterogeneidad del sistema productivo en la aplicación de la política regional: una propuesta para analizar la intermediación institucional

Avanzar en el abordaje de la influencia de la heterogeneidad en la intermediación institucional requiere retomar las herramientas conceptuales identificadas en los debates sobre las ventajas de las instituciones en el desarrollo y sobre la heterogeneidad en los sistemas productivos regionales. Teniendo en cuenta que 
hemos identificado ciertas limitaciones al momento de transformar estos cuerpos teóricos en política pública, a través del caso de la RMA (precisamente del análisis del nodo central que define el CMA) se busca demostrar las capacidades de sus vinculaciones teóricas para explicar la relación entre la heterogeneidad del sistema productivo y el diseño institucional que aplica la política pública.

La estrategia propuesta incorpora en primer lugar elementos que permiten interpelar al imaginario geográfico de homogeneidad regional. Se realiza un análisis morfológico del sistema productivo a partir de la variable tamaño operacionalizada según el performance de la empresa, es decir, según su grado de facturación. En el caso de estudio, el análisis de la morfología del nodo central del CMA presenta la heterogénea base pyme sobre la que se aplica la política pública. Como muestra la figura 6, si bien el sistema productivo del nodo central del CMA puede caracterizarse como un sistema productivo de pequeñas y medianas empresas, es decir pyme (por el peso relativo de ambos grupos de actores), la aparente homogeneidad interna se quiebra con la presencia de micros y grandes empresas.

Figura 6 - Nodo central CMA: heterogeneidad empresarial. Tamaño de los actores empresariales de la región según facturación derivada de los montos de venta (2009)

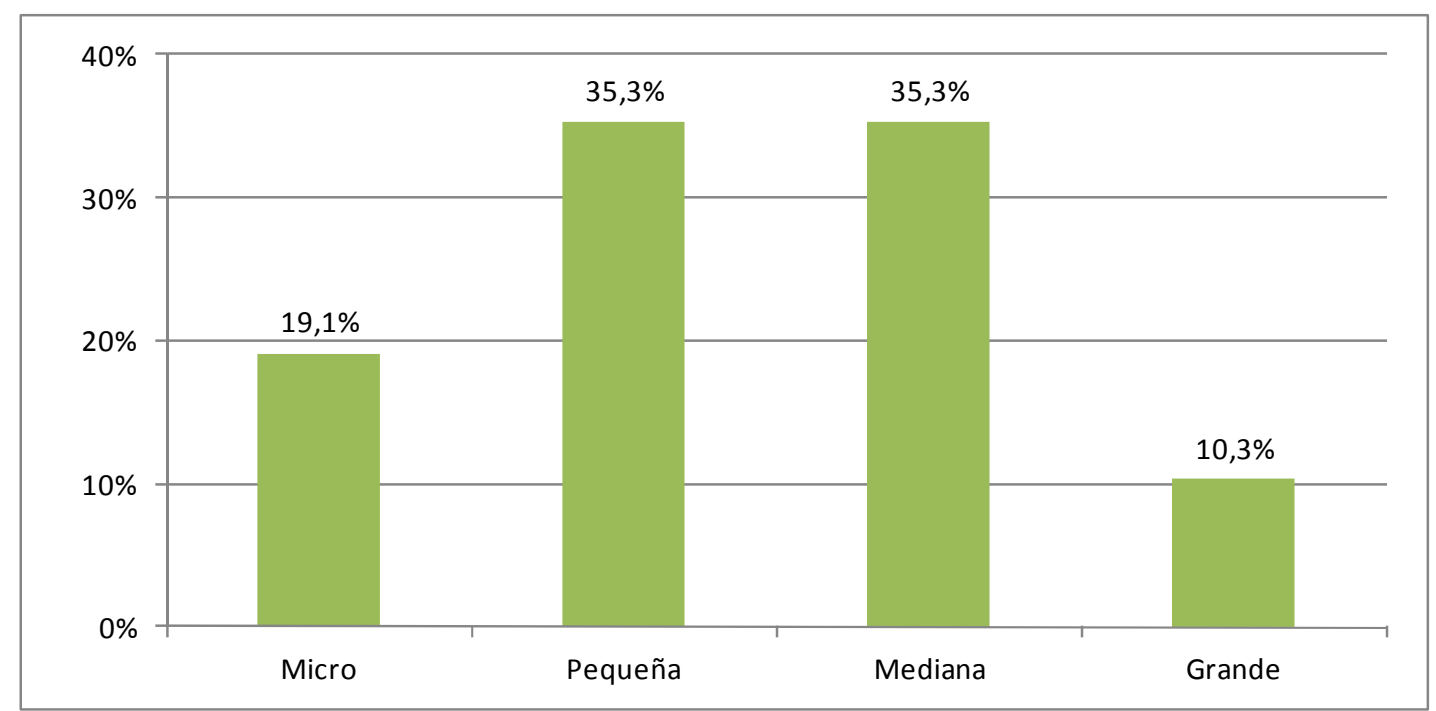

Fuente: Elaboración propia en base a encuestas (2009).

Descartado el imaginario geográfico de homogeneidad regional, en segundo lugar, se busca avanzar respecto al imaginario democrático de horizontalidad indagando la forma en que la morfología influye en la dimensión institucional. Las variables identificadas buscan analizar la conformación de las organizaciones en su interacción con los objetivos y herramientas de la política pública, es decir, las acciones de cooperación y las líneas de financiamiento. Se retomarán tres variables de la dimensión institucional operacionalizadas para detectar comportamientos selectivos: (1) la posesión de cargos de decisión en las organizaciones clave de la 
región (inserción organizacional), (2) el involucramiento en prácticas cooperativas (participación de acciones de cooperación) especificando además los tipos de prácticas que se movilizan (tipo de acciones de cooperación) y (3) la recepción de beneficios de los programas aplicados (recepción de financiamiento).

\section{La conformación de organizaciones en un contexto de actores heterogéneos}

La política pública comienza a interactuar con la selectividad de la dimensión institucional al potenciar la apertura democrática sin considerar que un contexto de actores heterogéneos puede influir la conformación de actores colectivos. La RMA pierde su característica pyme a nivel organizacional por la selectividad de la dimensión institucional. La apertura democrática reúne en la toma de decisión a un reducido grupo de actores regionales. En ese grupo están incluidos todos los grandes actores, que se posicionan como actores institucionales por su relevancia como actores económicos.

En este sentido, entre los grupos de actores regionales existe una diferencial inserción organizacional que lleva a las grandes empresas a posicionarse como el grupo con mayor capacidad para ubicar a sus representantes en cargos de decisión de organizaciones clave de la intermediación institucional del CMA. La heterogénea capacidad de los actores regionales para vincularse mutuamente y los heterogéneos resultados en la construcción de redes (institucionales, regionales y extra-regionales) juega un rol clave en un proceso que prácticamente no incluye micros ni pequeñas empresas (ver Figura 7).

Figura 7 - Nodo central CMA: inserción organizacional. Empresas con cargos en organizaciones del sector en los últimos 10 años, según grupos de actores regionales empresariales por tamaño (2010)

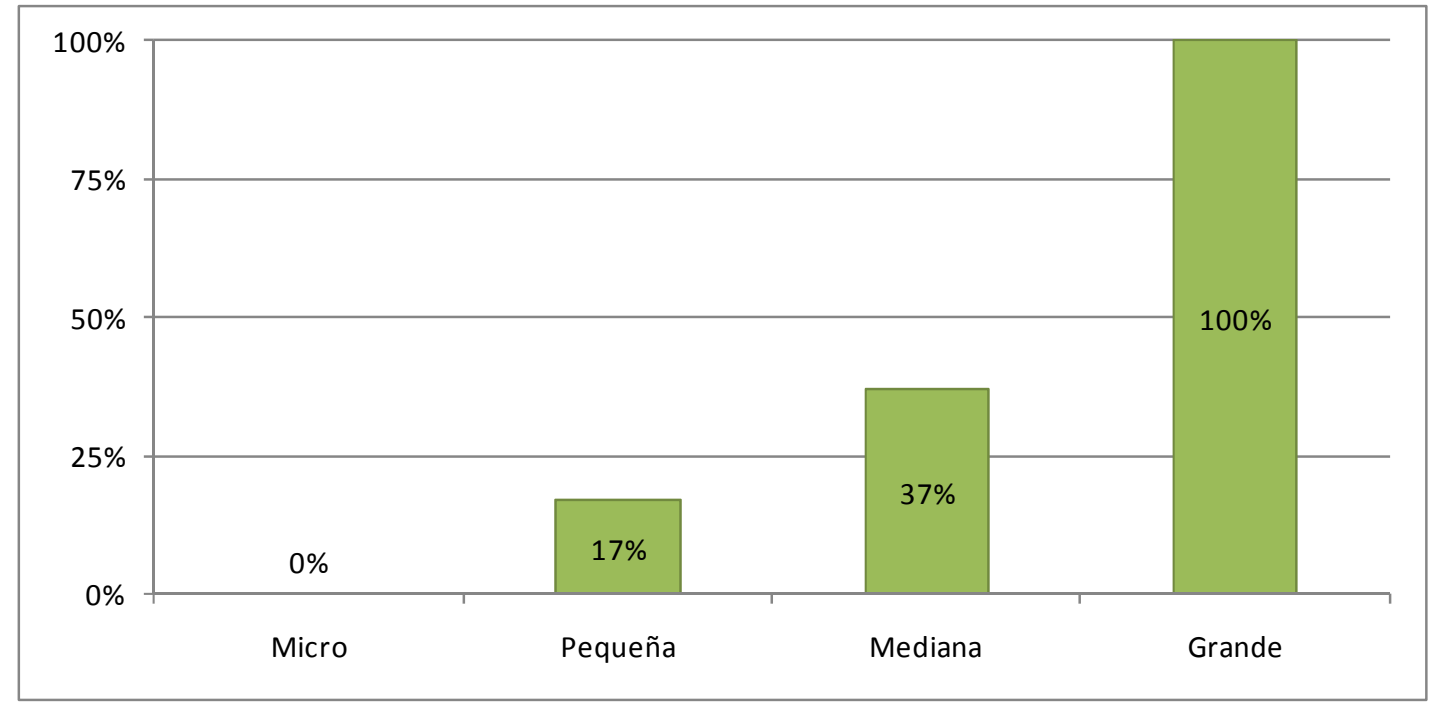

Fuente: Elaboración propia en base a encuestas (2009) e información documental. 
Los grandes actores merecen nuestra atención ya que son los únicos con plena inserción en la toma de decisión respecto a la política pública. Recordemos que el aumento de las exportaciones se encuentra entre los objetivos centrales del CMA, que el asociativismo busca mayor escala para ingresar a mercados internacionales y que las líneas de financiamiento promueven la incorporación de tecnología para cualificar el ingreso. La internacionalización es un objetivo que responde más a empresas con real capacidad de exportación que a la región como un todo. Esto no constituye un dato negativo siempre que el proceso sea capaz de cualificar los vínculos comerciales y no comerciales de la región.

\section{La cooperación en un contexto de actores heterogéneos}

La política pública fomenta la cooperación como elemento clave para lograr objetivos compartidos por los actores regionales. Este emergente cultural es cuestionable en el caso de la RMA. La práctica cooperativa no se encuentra generalizada y disminuye su capacidad de convocatoria con el tamaño de los actores empresariales. Los ambientes institucionales generados en la región (ver Cuadro 1) limitan la repercusión positiva del proceso de internacionalización en el sistema productivo regional porque dan lugar a la toma de posiciones por parte de grupos de actores regionales.

Si se relaciona este escenario con las advertencias teóricas sobre la selectividad del proceso cooperativo (SCHMITZ, 1999; 2000) la política pública se enfrentaría a un panorama cooperativo que podría generar efectos contrarios a los esperados. La selectividad señalada no puede afirmarse en términos categóricos en referencia al análisis aislado de la participación en acciones de cooperación porque la mayoría de los grupos poseen una participación similar (ver Figura 8).

La selectividad ingresa cuando se analiza el motivo de la cooperación a partir del tipo de acción de cooperación que se realiza. Se hacen presentes procesos de inclusión selectiva, en los que las micro-empresas se posicionan como las verdaderas excluidas de los resultados de la intermediación institucional (ver Figura 9). 
Figura 8 - Nodo central CMA: participación en acciones de cooperación. Representatividad de las empresas que realizan acciones conjuntas según tamaño de empresas por facturación (2008)

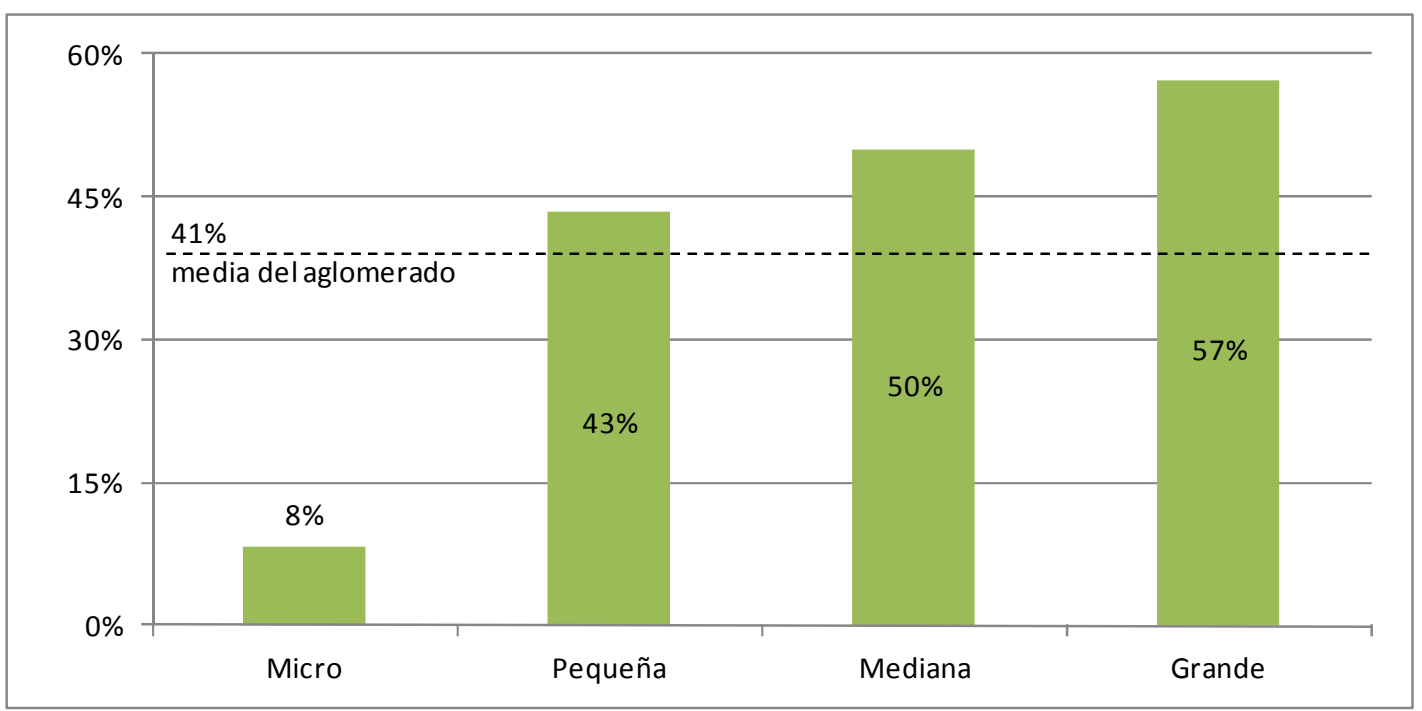

Fuente: Elaboración propia en base a encuestas (2009).

Figura 9 - Nodo central CMA: tipos de acciones de cooperación. Distribución porcentual de las empresas según tamaño de empresas por facturación (2008)

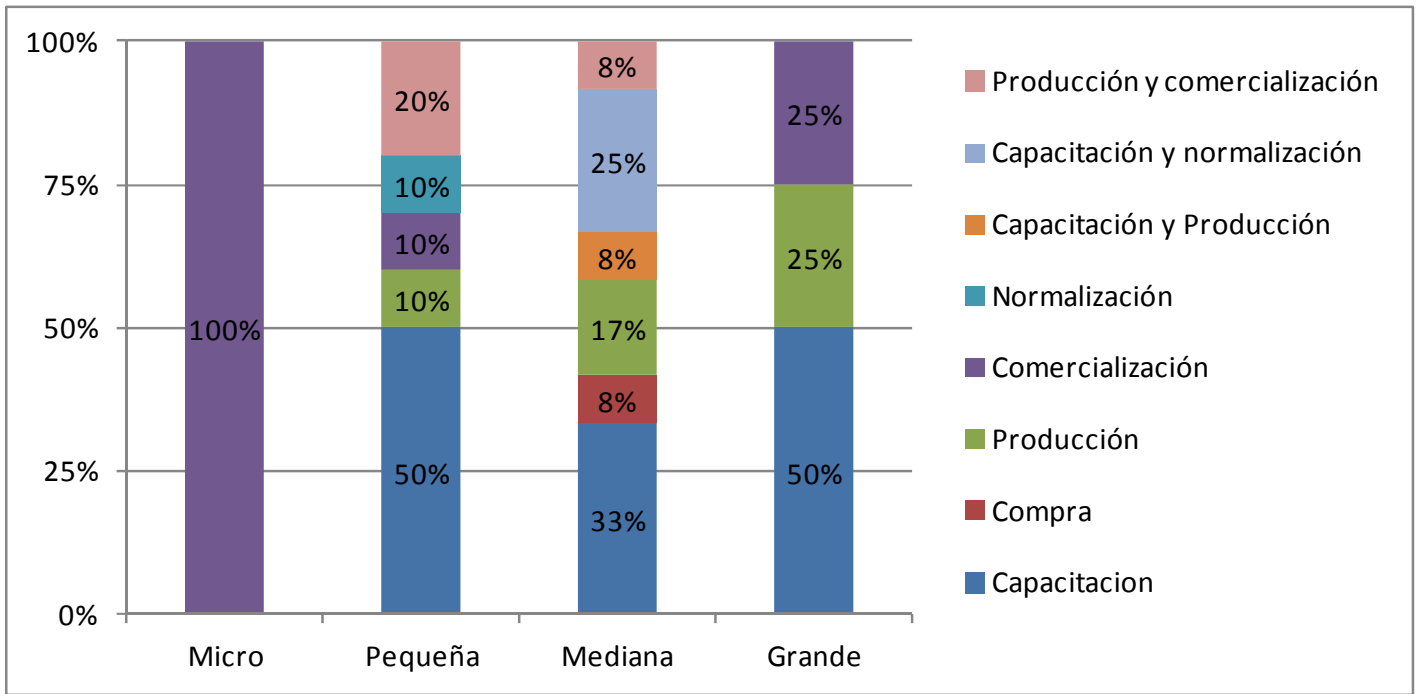

Fuente: Elaboración propia en base a encuestas (2009).

Al generar este panorama cooperativo desconsiderando las heterogeneidades entre los actores regionales, la política pública le aporta mayor flexibilidad a los grandes actores. Siguiendo la tipología de Morrison; Rabellotti (2005, 2009), pueden identificarse redes centrales y periféricas a la dinámica regional. La mayoría de las grandes empresas realizan acciones de cooperación con las empresas del sistema productivo para solucionar problemas de escala vinculados directamente a la venta de su producto. La relación con el resto del aglomerado se realiza a partir de 
vínculos dispersos que las posicionan en redes periféricas al un núcleo central de vinculaciones regionales. El núcleo, menos flexible, conformado por el grupo de pequeñas y medianas empresas, se ve atado a la lógica cooperativa regional por lo cual concentran todo el panorama cooperativo propuesto (Ver Figura 9).

En pocas palabras, las grandes empresas convocadas por la política pública para cooperar toman posiciones estratégicas en las que se ven beneficiadas directa e indirectamente. Por ejemplo, entre las vinculadas directamente al proceso de internacionalización, las estrategias de producción conjunta para el mercado internacional ${ }^{9}$ suelen vincular a grandes empresas entre sí mientras las misiones inversas $^{10}$ terminan beneficiándolas incluso cuando los seleccionados para la exportación son actores pequeños por las limitaciones para completar los stocks de exportación.

\section{El financiamiento en un contexto de actores heterogéneos}

La retroalimentación positiva entre los actores regionales también observa dificultades al tener en cuenta los beneficiarios directos del ingreso concreto de la política pública a través del financiamiento. Entre las diversas líneas de financiamiento $^{11}$, los Aportes No Reembolsables (ANR) se posicionan como el arquetipo del financiamiento a la innovación ${ }^{12}$. Son subsidios a la innovación que no deben ser devueltos, sin embargo, sólo financian la mitad del emprendimiento y las empresas tienen que tener la capacidad de costear el resto del proyecto. La selectividad viene dada por los requisitos de presentación y las obligaciones luego de la asignación, lo que puede dificultar la participación de varias empresas, por lo que la presentación de proyectos ANR se concentra entre las empresas medianas y grandes. Si bien las grandes empresas no tienen la mayor concentración de proyectos ni de asignación de ANR, fueron las más efectivas al recibir una mayor cantidad de adjudicaciones con una menor proporción de proyectos presentados (ver Figura 10), lo cual les permitió beneficios a todas las empresas en la última década (ver Figura 11).

\footnotetext{
${ }^{9}$ Caso del proyecto 315, tres empresas grandes asociadas para exportar a Venezuela (Ley Nac. $\mathrm{N}^{\circ}$ 26.631).

${ }^{10}$ Caso del Agroshowroom, misión inversa con muestra estática y dinámica (www.agroshow room.com.ar).

${ }^{11}$ Entre las líneas de financiamiento de AGENCIA se encuentran el PID, ANR, Crédito Fiscal (F), CAEFFIP, CAE I, Consultoría tecnológica (CT), entre las de SEPYME el CréditoFiscal (S) y el PRE, además de líneas de otros organismos como el CFI SF, la Ley de Innovación y AdimraTICs.

${ }^{12}$ Los ANR son la línea de mayor ejecución y la única que aumenta su ejecución en la región a partir de la aplicación de la intermediación institucional del CMA (CECMA-CIDETER; MASCHERONI, 2009)
} 
Las grandes empresas además de resolver la introducción de innovaciones en el proceso productivo con líneas de financiamiento de la política pública desarrollan estrategias individuales a través de la consolidación de vínculos externos. Es decir, se benefician de su posición como actores institucionales clave sin una gran relación con el aglomerado productivo en materia de cooperación porque entran en juego otros vínculos de sus propias redes tanto económicas como políticoinstitucionales.

Figura 10 - Nodo central CMA: ANR. Impacto de la heterogeneidad, según proyectos y asignación (2000-2008)

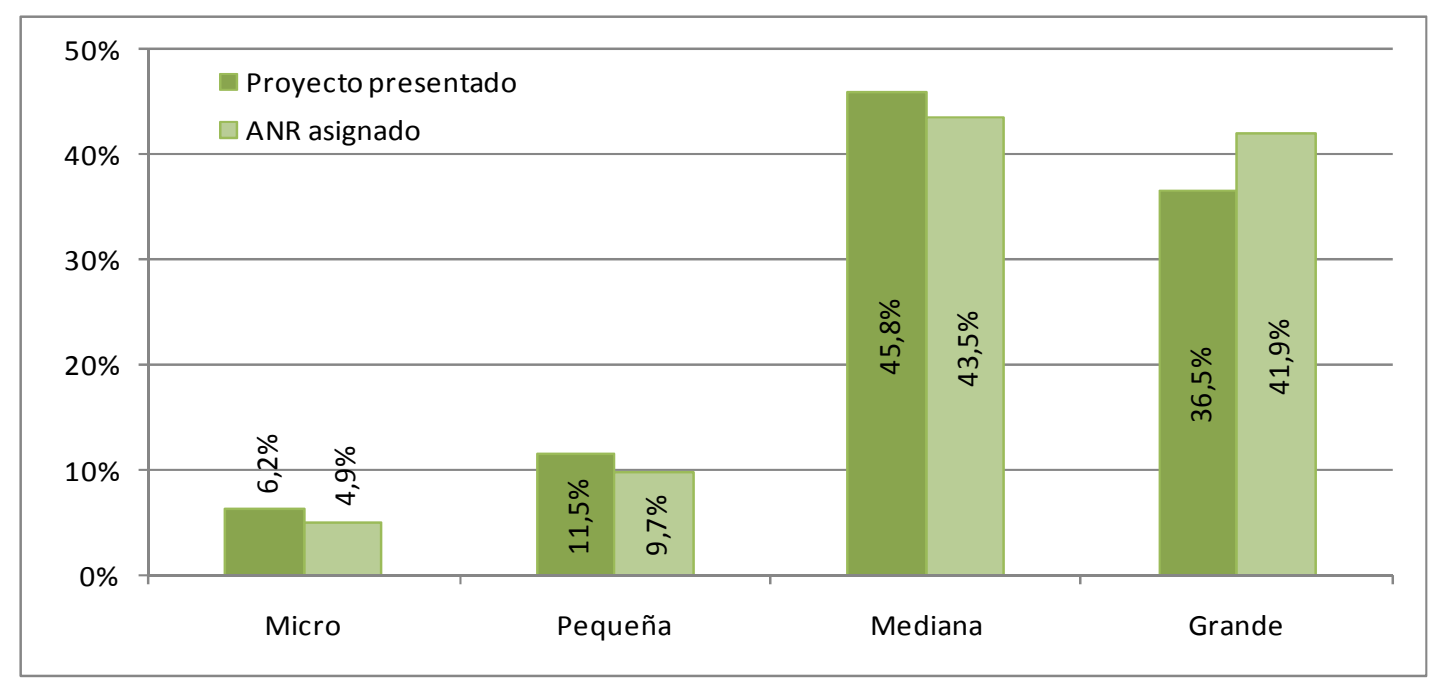

Fuente: Elaboración propia en base a datos de ANCYT (2010b).

Figura 11 - Nodo central CMA: ANR. Empresas beneficiadas, según tipo de empresa por facturación (2000-2008)

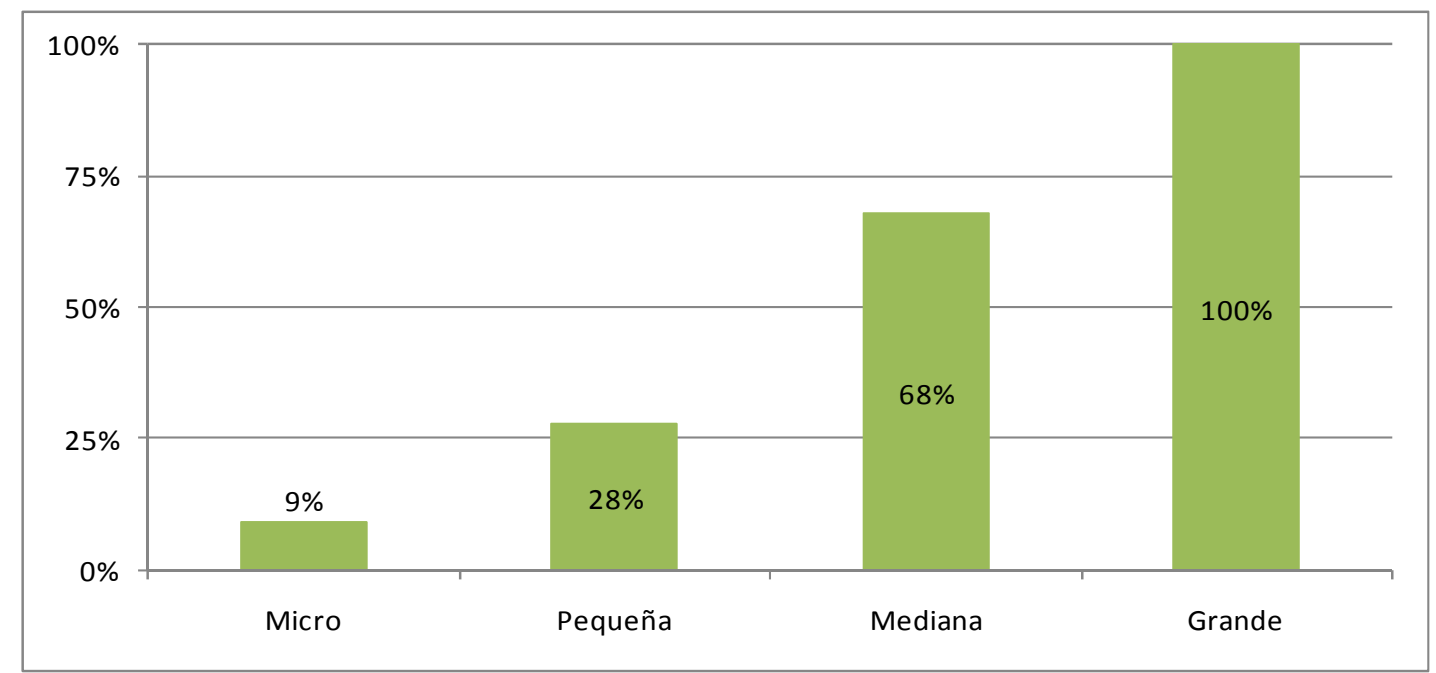

Fuente: Elaboración propia en base a datos de ANCYT (2010b). 


\section{La apertura de selectividades a partir de la intermediación institucional}

La intermediación institucional, si bien posibilita la actuación y generación de dinámicas productivas regionales, en el marco de las políticas de desarrollo regional también permite la apertura de selectividades. En ese proceso los actores más grandes logran posicionarse como actores claves en la toma de decisiones y consolidan su capacidad de hablar en nombre de la región. En la figura 12 se intenta resumir el proceso registrado en la RMA.

No se aprecia al grupo de los grandes actores regionales inmerso en el núcleo central de las redes regionales a pesar de su rol de actores institucionales imprescindibles en la aplicación de la política pública. El comportamiento de las grandes empresas se presenta periférico al aglomerado productivo, con vínculos débiles y efímeros. Yace en las medianas empresas la vinculación con el resto del entramado productivo conformado principalmente por los actores regionales no incluidos en la intermediación institucional. Entre los incluidos y los no incluidos, los primeros (derecha de la figura 12) son beneficiados directa o indirectamente por la aplicación de la política pública. Específicamente se observa mayor flexibilidad en las prácticas cooperativas y mayor efectividad en la obtención de financiamiento por parte de las grandes empresas, por la complejidad de su organización empresarial interna pero, sobre todo, porque tanto los objetivos como los instrumentos que intervienen son diseñados desde la institucionalidad local que controlan.

Figura 12 - Nodo central CMA: asimetrías regionales. Legitimación de las heterogeneidades a partir de la intermediación institucional

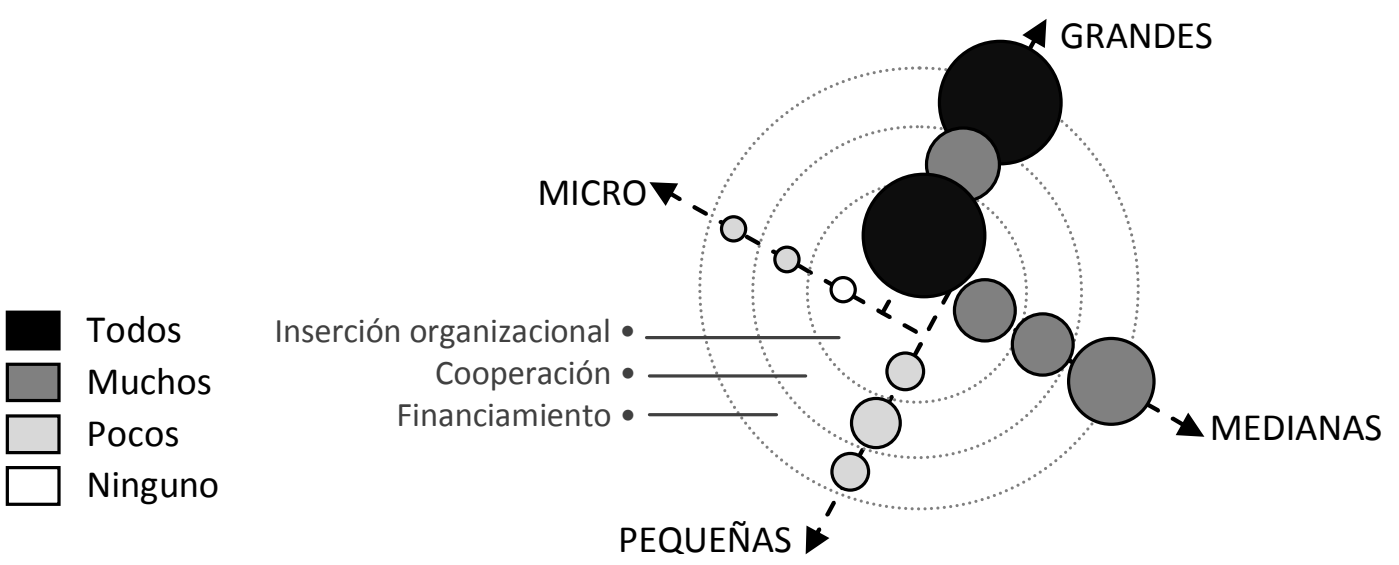

Fuente: Elaboración propia. 


\section{Conclusión}

La propuesta fue mostrar que la habilitación de selectividades por parte de la política pública tiene bases conceptuales vinculadas con un tipo específico de intermediación institucional impulsada desde debates teóricos más cercanos a la cohesión que al conflicto. Cuando se rompe con esa lógica comienza a apreciarse que las regiones y sus sistemas productivos poseen actores con tamaños dispares y dinámicas diversas que se yuxtaponen al diseño institucional. La selectividad viene dada por los posicionamientos estratégicos que toman aquellos actores que ostentan los mejores performances y adquieren la responsabilidad de conducir (o al menos guiar con gran capacidad de influencia) los destinos de la región.

Aquí radica un importante dilema en el que se encuentra la política de desarrollo regional, el evaluar la conveniencia de aplicar una política con resultados inclusivos poco claros. Un camino para resolverlo sería repensar el marco conceptual. No se trata de desconocer la teoría, sino de destacar sus elementos positivos y reconocer sus limitaciones. En el caso analizado, la política pública instala un imaginario geográfico de homogeneidad y un imaginario democrático de horizontalidad al adoptar de forma aislada a los aportes nuevo-regionalistas que resaltaron las ventajas de las instituciones locales en los procesos de desarrollo como base teórica de su accionar. En este sentido, darle continuidad al debate regionalista es clave, teniendo en cuenta la contribución de los aportes que discutieron las características de los sistemas productivos regionales. Si bien no responden la paradoja de forma directa, proporcionan herramientas conceptuales para avanzar en esa dirección al afirmar la existencia de heterogeneidad y su influencia en las prácticas de los actores regionales, dando cuenta de la articulación entre la heterogeneidad e institucionalidad.

El estudio de caso no pretendió discutir directamente al enfoque teórico que adopta la política pública desde el caso en sí, sino reflejar una crítica teórica y trabajar con aportes que la política pública no tuvo en cuenta. En ese sentido, el estudio de la RMA permitió ver lo que señala la teoría crítica, la heterogeneidad regional interna en los sistemas productivos existe. Considerar su existencia permite estudiar cómo se generan posicionamientos asimétricos entre los actores regionales a través de mecanismos institucionales. No es un dato menor en el marco de políticas públicas que buscan un desarrollo inclusivo a través del vínculo con una institucional regional que genera procesos de inclusión, como mínimo, selectivos. La intermediación institucional regional propuesta sin la problematización de la construcción regional que se potencia lleva a reconocer liderazgos que pueden observar problemas en la práctica dando lugar a estrategias individualistas/competitivas que garantizan beneficios particulares, no regionales. 


\section{Bibliografía}

AMIN, A. An institutionalist perspective on regional economic development. International Journal of Urban and Regional Research, Oxford, n. 23:2, p. 365-378, 1999.

AMIN, A.; THRIFT, N. Globalization, institutional thickness and local prospects. Revue d'Economie Regionale et Urbaine, Paris, n. 3, p. 405-427, 1994.

. Institutional issues for the European regions. Economy and Society, Abingdon, n. 24, p. 41-66, 1995.

ANPCYT. Proyecto integrado de aglomerados productivos. Buenos Aires: ANPCYT, 2010a.

. FONTAR Fondo Tecnológico Argentino de la Agencia Nacional de Promoción Científica y Tecnológica. Buenos Aires: ANPCYT, 2010b.

BAGNASCO, A. Tre Italia, la Problemática Territoriale dello Sviluppo Italiano. Bologna: II Mulino, 1977.

BECATTINI, G. Il Distretto Industriale Marshalliano: Cronaca di un Ritrovamento. In: BECAT'TINI, G. (Ed.) Mercato e Forza Locali: il Distretto Industriale. Bologna: II Mullino, 1987.

El distrito industrial marshalliano como concepto socioeconómico. In: PYKE, A.; BECATTINI, G.; SENGENBERGER W. (Eds.) Distritos industriales y las pequeñas empresas. Madrid: Ministerio de Trabajo y Seguridad Social de España, 1990.

BRACZYK, H.-J.; COOKE, P.; HEIDENREICH, M. Regional Innovation Systems: The Role of Governance in a Globalized World. London: UCL Press, 1998.

BIANCHI, P.; MILLER, L. Innovación, acción colectiva y crecimiento endógeno: un ensayo sobre las instituciones y el cambio estructural. In: BOSCHERINI, B.; POMA, L. (Comp.) Territorio, conocimiento y competitividad de las empresas. Buenos Aires: Miño y Dávila, 2000.

BRUSCO, S. The Emilian model: Productive decentralization and social integration. Cambridge Journal of Economics, Oxford, n. 6:2, p. 167-184, 1982. 
- El concepto de Distrito Industrial: su génesis. In: PYKE, F.; BECATTINI, G.; SENGENBERGER, W. (Comps.) Los distritos Industriales y las Pequeñas Empresas. Madrid: Ministerio de Trabajo y Seguridad Social de España, 1992.

CECMA. Acta constitutiva de Asociación Ad-Hoc C.E.C.M.A. No 249. Fo. 866. Las Parejas: CECMA, 2006a.

. Proyecto integrado del cluster de maquinaria agrícola y agro-partes de la región centro de Argentina que integran el conglomerado productivo. PI-TEC NA 002/06. Las Parejas: CECMA, 2006b.

CECMA: Interacción público/privada en la gestión de la innovación y productividad en el cluster. II Seminario internacional Estrategias para la Promoción Económica, EPSAM, 9 de Septiembre, 2011.

. Sector y Fabricantes de maquinaria agrícola y agropartes. Informe anual 2012. Las Parejas: CECMA, 2012.

CECMA-CIDETER; MASCHERONI, F. Centro Tecnológico CIDETER. Su inserción y rol en el Comercio Internacional de la Maquinaria Agrícola. Catamarca, Diciembre, 2009.

COOKE, P.; MORGAN, K. Learning through networking: regional innovation and the lessons of Baden-Wurttemburg. Cardiff: University of Wales, 1990.

. The associational economy. Firms, regions and innovation. New York: Oxford University Press, 1998.

CUMBERS, A.; MACKINNON, D.; MCMASTER, R. Institutions, power and space. Assessing the limits to institutionalism in economic geography. European Urban and Regional Studies, London, n. 10:4, p. 325-342, 2003.

DOLOREUX D.; PARTO S. Regional Innovation Systems: a critical review. Working Paper - Institute for New Technologies, Maastricht, 2005.

DONATO, V. N. Informe 2009-2010. Evolución reciente, situación actual y desafíos para 2011. Buenos Aires: Fundación Observatorio PYME, 2010.

GARCÍA, G. La industria argentina de maquinaria agrícola: ¿de la reestructuración a la internacionalización? Revista de la CEPAL, Santiago de Chile, n. 96, p. 221237, 2008. 
GIULIANI, E. The structure of cluster knowledge networks: uneven and selective, not pervasive and collective. Working Paper DRUID, Copenhagen, n. 05:11, 2005.

GIULIANI, E.; BELL, M. The micro-determinants of meso-level learning and innovation: evidence from a Chilean wine cluster. Research Policy, London, n. 34:1, p. 47-68, 2005.

GSF. Cadena de la Maquinaria Agrícola Santafesina. Una nueva visión para la producción y el desarrollo. Santa Fe: Ministerio de la Producción, Gobierno Provincia de Santa Fe, 2009.

HADJIMICHALIS, C. Factores no económicos en la geografía económica y en el 'nuevo regionalismo': una crítica amistosa. In: FERNÁNDEZ, V. R.; AMIN, A; VIGIL, J. I. (Eds.) Repensando el desarrollo regional. Contribuciones globales para una estrategia latinoamericana. Buenos Aires: Miño y Dávila, p. 247-265. 2008.

KEATING, M. The New Regionalism. In: Western Europe. Territorial restructuring and political change. Cheltenham: Edward Elgar, 1998.

LOVERING, J. Theory Led by Policy: the inadequacies of the "New Regionalism". International Journal of Urban and Regional Research, Oxford, n. 23:2, p. 379-395, 1999.

MARKUSEN, A. Sticky places in slippery space: a typology of industrial districts. Economic Geography, Worcester, n. 72:3, p. 293-313, 1996.

MARTIN, R.; SUNLEY, P. Deconstructing clusters: chaotic concept or policy panacea? Journal of Economic Geography, Oxford, n. 3:1, p. 5-35, 2003.

MASKELL, P. The firm in economic geography. Economic Geography, Oxford, 77:4, p. 329-344, 2001.

MCEVILY, B.; ZAHEER, A. A Source of Firm Heterogeneity in Competitive Capabilities. Strategic Management Journal, Oxford, n. 20:12, p. 1133-1156, 1999.

MI. Plan Estratégico Industrial 2020. Buenos Aires: Ministerio de Industria, Presidencia de la Nación Argentina, 2011.

. Programas y Beneficios para la industria. Buenos Aires: Ministerio de Industria, Presidencia de la Nación Argentina, 2013. 
MOLINA-MORALES, F. X.; MARTÍNEZ-FERNÁNDEZ, M. T. Does homogeneity exist within industrial districts? A social capital-based approach. Papers in Regional Science, Oxford, n. 88:1, p. 209-229, 2009.

MORRISON, A.; RABELLOT'TI, R. Knowledge and information networks: Evidence from an Italian wine local system. Working Papers CESPRI, Milan, n. $174,2005$.

- Knowledge and information networks in an Italian Wine Cluster. European Planning Studies, London, n. 17:7, p. 983-1006, 2009.

MPFIPS. Argentina 2016. Política y Estrategia Nacional de Desarrollo y Ordenamiento Territorial. Buenos Aires: Ministerio de Planificación Federal, Inversión Pública y Servicios, Presidencia de la Nación Argentina, 2004.

NACLERIO, A. Sistemas productivos locales: políticas públicas y desarrollo económico. Buenos Aires: Programa Naciones Unidas para el Desarrollo, 2010.

NARODOWSKI, P. La escala local, desde la periferia. Análisis de la industria de maquinaria agrícola en Las Parejas (provincia de Santa Fe, Argentina) relacionada con su contexto, dentro de la economía Argentina". Geograficando, La Plata, n. 3:3, p. 67-88, 2007.

PANICCIA, I. One, a Hundred, Thousands of Industrial Districts. Organizational Variety in Local Networks of Small and Medium-sized Enterprises. Organization Studies, London, n. 19:4, p. 667-699. 1998.

- The performance of IDs. Some insights from the Italian case. Human Systems Management, Amsterdam, n. 18:2, p. 141-159, 1999.

PORTER, M. La ventaja competitiva de las naciones. Buenos Aires: Ed. Vergara, 1990.

Clusters and the New Economics of Competition. Harvard Business Review, Boston, n. 76:6, p. 77-90, 1998.

PUTNAM, R. D.; LEONARDI, R.; NANETTI, R. Y. Making Democracy Work. Princeton: Princeton University Press, 1993.

RABELLOTTI, R. Recovery of a Mexican Cluster: Devaluation Bonanza or Collective Efficiency? World Development, London, n. 27:9, p. 1571-1585, 1999. 
RABELLOTTI, R.; SCHMITZ, H. The internal heterogeneity of industrial districts in Italy, Brazil and Mexico. Regional Studies, Oxford, n. 33:2, p. 97-108, 1999.

RODRÍGUEZ-POSE, A. Instituciones y desarrollo económico. Ciudad y Territorio. Estudios Territoriales, Madrid, n. 31:122, p. 775-784, 1999.

SCHMITZ, H. Global Competition and Local Cooperation: Success and Failure in the Sinos Valley, Brazil. World Development, London, n. 27:9, p. 1627-1650, 1999.

Does local co-operation matter? Evidence from industrial clusters in South Asia and Latin America. Oxford Development Studies, Oxford, n. 28:3, p. 323-336, 2000.

SEPYME. Reglamento Operativo Proyecto PNUD ARG/05/024. Promoción de Clusters y Redes Productivas con Impacto en el Desarrollo Regional. Buenos Aires: SEPYME, 2005.

Sistemas Productivos Locales. SEPYME (Secretaría PYME y Desarrollo Regional). Buenos Aires: SEPYME, 2011.

SHAVER, J. M.; FLYER, F. Agglomeration Economies, Firm Heterogeneity, and Foreign Direct Investment in the United States. Strategic Management Journal, Oxford, n. 21:2, p. 1175-1193, 2000.

STORPER, M. The regional world. Territorial development in a global economy. New York-London: The Guilford Press, 1997.

STORPER, M.; HARRISON, B. Flexibilidad, jerarquía y desarrollo regional: Los cambios de estructura de los sistemas productivos industriales y sus nuevas formas de articulación del poder en los años 90. In: BENKO G.; LIPIETZ, A. (Comp.) Las regiones que ganan. Distritos y redes. Valencia: Edicions Alfons El Magnánim, 1994.

VIGIL, J. I.; FERNÁNDEZ, V. R. Gobernanza y Dinámicas Productivas de Desarrollo Regional. Santa Fe: Ediciones UNL, 2011.

WALKER, R. Foreword. In: HEROD, A. (Ed.) Organising the Landscape: Geographical Perspectives on Labour Unionism. London: University of Minnesota Press, 1998. 
Endereço para correspondência:

MartinSeval-martinseval@yahoo.com.ar Lavalle 6779

CP 3000 Santa Fe de la Vera Cruz/Santa Fe, Argentina

José Ignacio Vigil- jvigil@ffce.unl.edu.ar

Moreno 2557, Instituto de Investigación Estado Territorio y Economía

CP S3000CVE Santa Fe, Argentina

Victor Ramiro Fernández - rfernand@fcjs.unl.edu.ar

Moreno 2557, Instituto de Investigación Estado Territorio y Economía CP S3000CVE Santa Fe, Argentina 